\title{
Steroids Alone, Versus Steroids with Antihistamines, in the Treatment of Oral Lichen Planus - A Comparative Study from Chennai, India
}

\author{
Deepigaa Manivasagam ${ }^{1}$, Arvind Muthukrishnan ${ }^{2}$ \\ 1,2 Department of Oral Medicine and Radiology, Saveetha Institute of \\ Medical and Technical Sciences (SIMATS), Kuthambakkam, Tamil Nadu, India.
}

\section{ABSTRACT}

\section{BACKGROUND}

Lichen planus (LP) is a chronic T cell mediated autoimmune disorder affecting the skin and mucosa of the oral cavity. Mainstays of treatment are corticosteroids which are mostly used topically, and severe cases require systemic management. Recalcitrant or severe cases may require steroid sparing immune-modulators. Mast cells are predominant in the active phase of LP and antihistamines reduce mast cell numbers. The purpose of this study was to evaluate the effectiveness of antihistamines in oral lichen planus.

\section{METHODS}

This study was conducted from June 2019 to March 2020 in oral medicine department. A total of 54 patients were included in which group - $1(n=27)$ patients were treated with both systemic antihistamine with topical steroids, group $-2(n=27)$ patients were treated with topical steroids only. The Challacombe scale was used to assess the severity of disease at baseline, 15 days and 30 days.

\section{RESULTS}

Results showed that patients were in the age group of 51 - 60 years (27.8\%), female predilection (63\%), erosive OLP (50\%) and reticular OLP (38.8\%) was most commonly reported. Mean difference and standard deviation at first review and second review for group 1 was $9.85 \pm 2.349,8.14 \pm 2.685$; group 2 was $4.74 \pm 2.297$, $4.37 \pm 2.436$ respectively with a statistically significant value $(<0.05)$. In between the reviews, group - 1 showed a rapid reduction in severity of disease when compared to group - 2 .

\section{CONCLUSIONS}

A combined therapy of topical steroids and systemic antihistamines was more effective in active reduction of disease and are easily available with no adverse effects reported.

\section{KEY WORDS}

Antihistamines; Challacombe Scale; Mast Cells; Oral Lichen Planus
Corresponding Author: Dr. Arvind Muthukrishnan, Saveetha Institute of Medical and Technical Sciences (SIMATS), Kuthambakkam, Tamil Nadu, India. E-mail: arvindm@saveetha.com

DOI: $10.14260 /$ jemds/2021/665

How to Cite This Article:

Manivasagam D, Muthukrishnan A. Steroids alone, versus steroids with antihistamines, in the treatment of oral lichen planus - a comparative study from Chennai, India. J Evolution Med Dent Sci 2021;10(37):3277-3282, $10.14260 /$ jemds/2021/665 DOI:

Submission 03-06-2021,

Peer Review 21-08-2021,

Acceptance 27-08-2021,

Published 13-09-2021.

Copyright (C) 2021 Deepigaa Manivasagam et al. This is an open access article distributed under Creative Commons Attribution License [Attribution 4.0 International (CC BY 4.0)] 


\section{BACKGROUND}

Lichen planus was first described by Sir William James Erasmus Wilson in 1869 and Dubdreuin histologically evaluated it in 1906. It is a chronic or recurrent inflammatory immune mediated disease of oral mucosa typically characterised by presence of white lace-like lesions, with or without erosive areas. ${ }^{1}$ It is a T cell mediated autoimmune disease $^{2}$ where the Langerhans cells obtain peripheral antigens and present them to $\mathrm{T}$ cells. ${ }^{3}$ The activated $\mathrm{T}$ cells are accompanied by cytokine secreting natural killer cells leading to apoptosis of basal keratinocytes. ${ }^{4}$ Histologically, the degenerating basal keratinocytes form colloid bodies and appear as homogenous eosinophilic globules. ${ }^{5}$ It is then followed by liquefaction of basal epithelium and connective tissue resulting in focal areas of hyperkeratosis that manifests clinically as Wickham's striae. ${ }^{6}$

Worldwide incidence of oral lichen planus (OLP) is $5 \%$ approximately. ${ }^{7}$ These lesions are bilaterally symmetrical lesions and are commonly found on buccal mucosa, gingiva and tongue. ${ }^{8}$ They may or may not be presented with extra oral lesions. ${ }^{7}$ Studies have reported approximately $15 \%$ of OLP are accompanied with skin lesions. ${ }^{4}$ The varied etiological factors such as genetic background, drugs, diabetes, hypertension, immunodeficiency, infectious agents, autoimmunity, food and dental allergy, habits, trauma, occupation, stress and poor oral hygiene may act as a trigger factor. Clinically, OLP are classified into seven subtypes by World Health Organization (WHO) namely reticular, erosive, atrophic, papular, plaque like, bullous and ulcerated. ${ }^{9}$ The prevalence rate of oral lesions in South India is $4.1 \% .^{10}$ The malignant transformation rate of OLP is $0.04 \%-1.74 \% .{ }^{11}$ Highest malignant transformation is reported in erosive OLP.12

Topical steroids are the first line of treatment for mild to moderate OLP. Intralesional steroids are used for managing severe and more localized forms of OLP. ${ }^{13}$ In severe patients who do not respond to topical management, systemic steroids such as prednisolone are usually prescribed. Recalcitrant or steroid resistant cases are managed effectively with calcineurin inhibitors such as tacrolimus, pimecrolimus, ciclosporin and other steroid sparing immunomodulators such as azathioprine. ${ }^{14}$ Other medications include retinoids, thalidomide, metronidazole, griseofulvin and hydroxychloroquine, UV phototherapy, photodynamic therapy and lasers. ${ }^{15}$ Recent evidence for managing OLP is by using natural therapeutic agents such as lycopene, vitamin $\mathrm{E}$, vitamin $\mathrm{C}$ curcumin, aloe vera, licorice and green tea.

Antihistamines inhibit DNA binding activity of NF-Kappa B inhibitors expression of adhesion molecules (ICAM - 1) on immunocytes and endothelial cells. ICAM - 1 is over expressed in LP. ${ }^{16}$ Mast cells (MC) are usually increased in number and are in activated state in LP. ${ }^{17}$ They reduce the number of tryptase positive MC in inflammation sites. ${ }^{18}$ Antihistamines have already proved its efficacy in management of psoriasis, ${ }^{18}$ erythema gyratum repens, ${ }^{19}$ lichen nitidus, ${ }^{20}$ lichen planopilaris, ${ }^{21}$ cutaneous lichen ruber planus. Thus, the aim of this study was to evaluate the effectiveness of antihistamines in oral lichen planus.

\section{METHODS}

A retrospective study was conducted in the Oral Medicine Department of The University Dental Hospital. The research was approved by the institutional ethical committee and scientific review board (SRB). Two researchers were involved in the study, one was the primary researcher and other was the department faculty.

The study was done from June 2019 to March 2020 and all other details were collected from the department record base. Patient details with incomplete records were excluded from the study. Patient details with incomplete records were not included in the study. Sample size calculation was done using $\mathrm{G}$ power analysis software and calculated to the power of $80 \mathrm{~A}$ total of 54 patients $(\mathrm{M}=20, \mathrm{~F}=34)$ were included in the study.

This study included new untreated cases of lichen planus and who reported for 3 visits to the department after commencement of treatment. 27 patients (group 1) were treated with topical steroids and systemic antihistamines (cetirizine $10 \mathrm{mg}$ ); 27 patients (group - 2) were treated with topical steroids alone. Oral disease severity score index (Challacombe scale) ${ }^{22}$ was used to assess the severity of disease at baseline, first visit and second visit.

\section{Statistical Analysis}

The statistical software used for analysis was IBM Statistical Package for Social Sciences (SPSS version20). Descriptive analysis was performed for assessing correlation and association and chi square test was performed to evaluate the level of significance. A paired $t$ test was used to assess the effectiveness of the drug at baseline, first visit and second visit.

\section{RESULTS}

In this study, 54 OLP patients were involved, 27 patients were treated with topical steroids and systemic antihistamines while another 27 patients were treated with topical steroids only. The frequency distribution of age of OLP were maximum in 51 - 60 years $(27.8 \%)$ followed by 41 - 50 years (22.2\%); 31 - 40 years $(20.4 \%) ; 21$ to 30 years (18.5\%); 61 to 70 years (9.3\%) and 71 to 80 years $(1.9 \%)$. OLP was predominant in females (62.9\%) and male (37.04 $\%)$ respectively.

Frequency distribution of type of OLP are highest in erosive OLP (50 \%) followed by reticular (38.8\%); pigmented (3.7\%); annular (1.8\%); atrophic (1.8\%); bullous $(1.8 \%)$ and papular (1.8\%) [graph - 1]. Right and left buccal mucosa with gingiva is reported in $33.3 \%$ followed by bilateral buccal mucosa in $27.7 \%$; bilateral buccal mucosa with gingiva and dorsal surface of tongue in $11.1 \%$; right and left buccal mucosa with upper lip, lower lip and gingiva in $9.26 \%$; right and left buccal mucosa with upper lip and gingiva in $9.26 \%$; bilateral buccal mucosa with lower lip in $1.85 \%$; bilateral buccal mucosa with upper lip and lower lip in $1.85 \%$ [graph - 2]. Descriptive analysis for age and type of lichen planus using a chi square test revealed erosive lichen planus was commonly seen in 51 to 60 years; reticular lichen 
planus was seen in 31 - 40 years and 41 to 50 years; atrophic OLP in 21 to 30 years and annular in 41 to 50 years; P $>0.05$ [graph - 3]. Erosive OLP was more commonly seen in females followed by males [graph 4]. Mean and standard deviation in group 1 at baseline, first visit and second visit is $49.78 \pm$ $6.693,39.93 \pm 6.850,31.178 \pm 6.259$ and for group 2 is 41.56 $\pm 8.759,36.81 \pm 8.871$ and 32.449 .048 respectively [Table $1]$.

A paired $t$ test was performed to assess the statistical difference of group - 1 at baseline and first visit, first visit and second visit showed $\mathrm{P}>0.05$ with mean and SD $9.852 \pm$ $2.349,8.148 \pm 2.685$ respectively. Statistical difference of group 2 at baseline and first visit, first visit and second visit is $\mathrm{P}>0.05$ with mean and SD as $4.74 \pm 2.297 ; 4.370 \pm 2.436$ respectively [Table 1].

The disease severity assessed using Challacombe scale revealed the difference of mean in group 1 at baseline and second review is $7.75 \%$ and in group 2 at baseline and second review is $3.99 \%$.
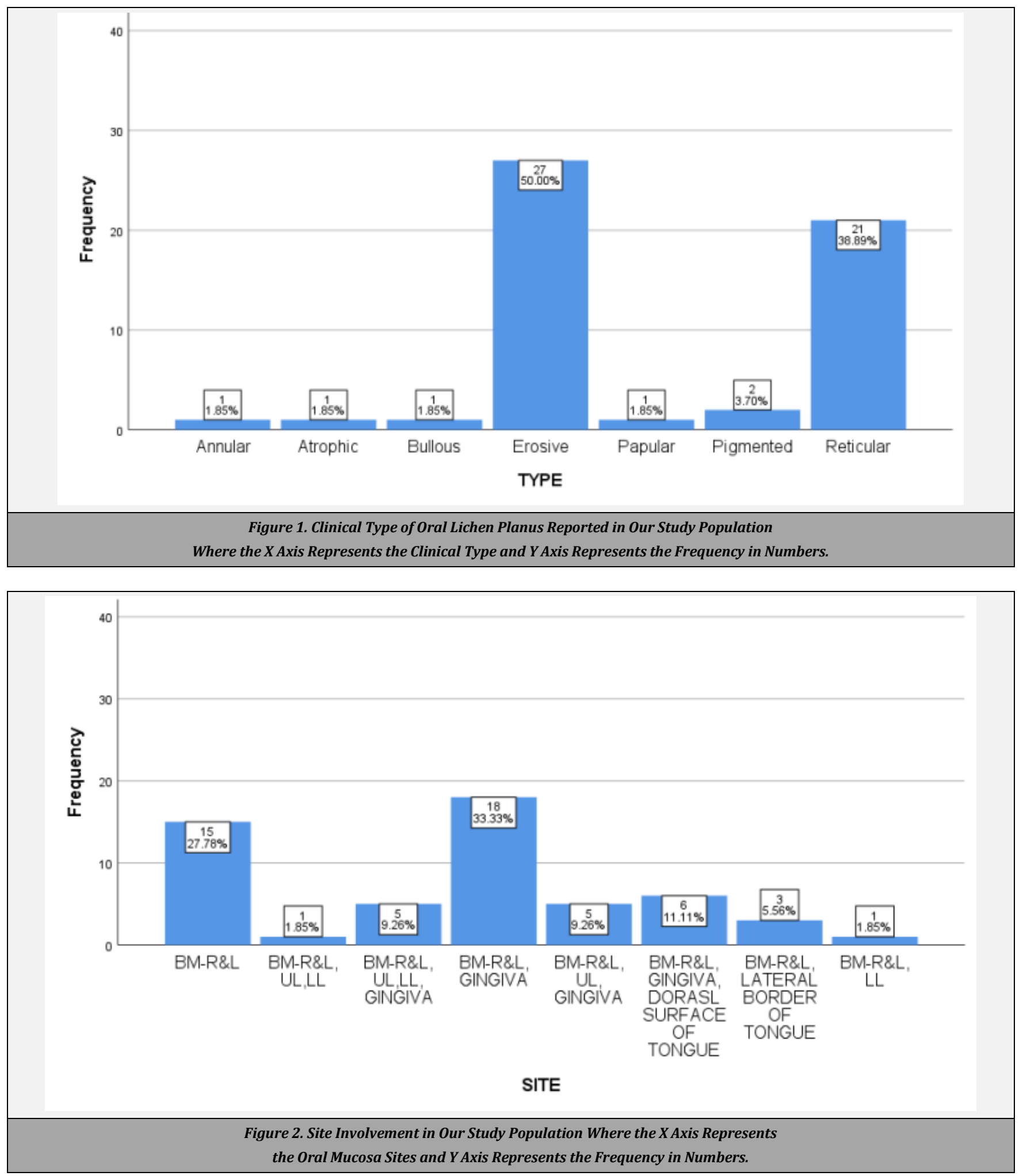

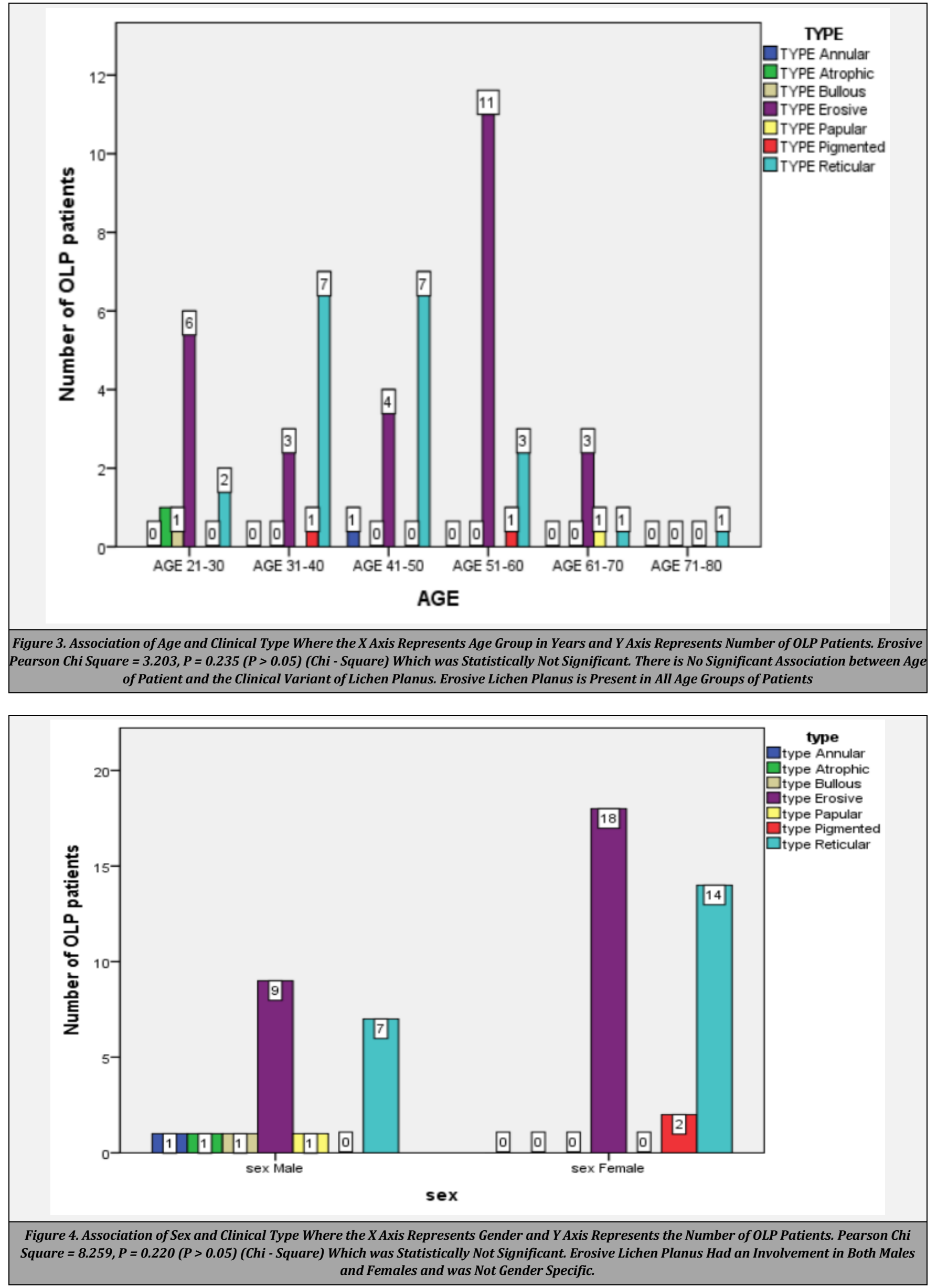


\begin{tabular}{|c|c|c|c|}
\hline & Baseline & $\begin{array}{l}\text { First Review } \\
\text { (15 days) }\end{array}$ & $\begin{array}{l}\text { Second Review } \\
\text { (30 days) }\end{array}$ \\
\hline Group 1 mean \pm Std dev & \multicolumn{3}{|c|}{$49.78 \pm 6.69339 .93 \pm 6.85031 .178 \pm 6.259$} \\
\hline Group 2 mean \pm Std dev & \multicolumn{2}{|c|}{$41.56 \pm 8.75936 .81 \pm 8.871$} & $32.44 \pm 9.048$ \\
\hline $\begin{array}{l}\text { Group } 1 \text { percentage of } \\
\text { reduction }\end{array}$ & 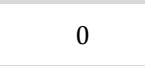 & $9.85 \pm 2.349$ & $8.14 \pm 2.685$ \\
\hline $\begin{array}{l}\text { Group } 2 \text { percentage of } \\
\text { reduction }\end{array}$ & 0 & $4.74 \pm 2.297$ & $4.37 \pm 2.436$ \\
\hline Group $1 \mathrm{P}$ value & 0 & 0.000 & 0.000 \\
\hline Group 2 P value & 0 & 0.000 & 0.000 \\
\hline $\begin{array}{r}\text { Table 1. Mean Dise } \\
\text { and du }\end{array}$ & Severity $S$ & $\begin{array}{l}\text { ore at Pre - Tr } \\
\text { Treatment }\end{array}$ & ttment \\
\hline
\end{tabular}

\section{DISCUSSION}

Lichen planus is an immune mediated dermatological condition of unknown aetiology. It was identified in 1869 as an inflammatory disorder of stratified squamous epithelium and was named from Greek lichen meaning moss and planus meaning flat. 4 They are recognised as per 6 P's namely pruritic, papular or plaque like lesions, purple colour, polygonal shape and planar surface. ${ }^{4}$ They commonly affect the flexor surfaces, hair, nails, oral and vulvovaginal mucosa. ${ }^{23}$ They are autoimmune and inflammatory in nature associated with a $\mathrm{T}$ cell mediated reaction. In oral cavity, they may range from asymptomatic keratosis spots to painful ulcerations $^{24}$ and affect the quality of life. International association for the study of pain (IASP) defines pain as an unpleasant sensory and emotional experience associated with actual or potential tissue damage or described in terms of such damage. ${ }^{25,26}$

The Challacombe scale is a modified scoring system which was used for mucous membrane pemphigoid.27 The oral cavity was divided into 17 sites, a minimal score from 0 to 2 was given for site, 0 to 3 for severity of lesion and activity of disease was calculated by multiplying the site score and severity score. A self-assessed pain score ranging from 0 to 10 was used to record patient pain experience. The maximum site score was 24 and activity score was 72 . A cumulative score was calculated from site score, activity score and pain score, the maximum score recorded was 106.22

The aim of any treatment is to reduce the symptoms of the disease. Mast cells may act as a "key factor " in the active phase of oral and cutaneous LP. ${ }^{17}$ In OLP, MCs are increased in epithelial and connective tissue junctions where there is evidence of membrane disruption. ${ }^{28}$ An anxiolytic and antihistaminic activity drug hydroxyzine has been effective in LP in the United States. Cetirizine has proved to possess antiinflammatory properties and has the ability to reduce expression of ICAM - 1 and number of MC. 18

Based on present study, oral lichen planus was predominant in 51 to 60 years $(27.8 \%)$ with a female predilection (63\%). Sherlin et al. in his study reported that OLP was more common in 55 to 70 years $^{29}$ and Dorinda a Laurirano et al. in his study has reported that females are more commonly affected and are more often in 5th and 6th decades of life. ${ }^{30}$ The most common clinical variant reported in our study is erosive (50\%) and reticular (38.8\%) with buccal mucosa common site observed. Vice Budimir reported in his study that reticular lichen planus was more reported in his study followed by erosive OLP and buccal mucosa, the most common site observed. ${ }^{31}$ Our study reported that erosive lichen planus was more common in 51 to 60 years and reticular in 41 to 50 years.

Topical steroids for management for OLP have been proved to be effective with less adverse effects and require long term management ${ }^{32}$ whereas on the other hand, antihistamine have also been proved to be safe, effective, with no adverse effects and reduces the treatment duration. Group - 1 patients had rapid reduction in severity of disease after 30 days and were statistically significant. Sharma L et al. in his study had reported that topical steroids with antihistamines are effective in management of OLP. ${ }^{33}$ Group 2 patients also had a reduction in disease severity, but significant reduction was recorded in group - 1 patients who were treated with systemic antihistamines.

Limitation of this study is that it requires long term follow-up of more subjects and multi centric trials.

\section{CONCLUSIONS}

Oral lichen planus is a T cell mediated immunological disease and mast cells play an important role in the active phase of LP. Antihistamines have anti-inflammatory action and also reduces the number of tryptase positive MC in inflammation sites. Thus, a combined therapy of topical steroids with antihistamines systemically are more effective in active reduction of disease, reducing the treatment time, more economical with no adverse effects reported.

\section{Clinical Significance}

Antihistamines prove to be a viable alternative to corticosteroids in the management of oral lichen planus as it is more economical and with negligible side effects.

Data sharing statement provided by the authors is available with the full text of this article at jemds.com.

Financial or other competing interests: None.

Disclosure forms provided by the authors are available with the full text of this article at jemds.com.

The authors are grateful to Saveetha Institute of Medical and Technical Sciences for granting permission to conduct the present study and the faculties of Department of Oral Medicine for their critical review, support during the development and writing of these manuscripts.

\section{REFERENCES}

[1] Warnakulasuriya S, Johnson NW, van der Waal I. Nomenclature and classification of potentially malignant disorders of the oral mucosa. J Oral Pathol Med 2007;36(10):575-80.

[2] Nirisha S, Gheena S. Comparing the efficacy of haematoxylin and eosin ( $\mathrm{H}$ and $\mathrm{E}$ ) and periodic acid schiff (pas) for demonstration of basement membrane in lichen planus. International J of Multidisciplinary Research and Modern Education 2017;3(2):26-8.

[3] Georgakopoulou EA, Achtari MD, Achtaris M, et al. Oral lichen planus as a preneoplastic inflammatory model. J Biomed Biotechnol 2012;2012:759626. 
[4] Gorouhi F, Davari P, Fazel N. Cutaneous and mucosal lichen planus: a comprehensive review of clinical subtypes, risk factors, diagnosis and prognosis. Scientific World Journal 2014;2014:742826.

[5] Karthikeson PS, Kumar VJ. Oral lichen planus - a review. Res J Pharm Biol Chem Sci 2020;12(1):196-8.

[6] Doebel T, Voisin B, Nagao K. Langerhans cells - the macrophage in dendritic cell clothing. Trends Immunol 2017;38(11):817-28.

[7] Cooper AJ. A review of oral lichen planus for the dental professional. International J of Dentistry and Oral Health 2019;5(1):1-5.

[8] Radwan-Oczko M, Zwyrtek E, Owczarek JE, et al. Psychopathological profile and quality of life of patients with oral lichen planus. J Appl Oral Sci 2018;26:e20170146.

[9] Prabakaran SP, Muthukrishnan A. Expression of cytokeratin 18 and 19 in oral potentially malignant disorders: a systematic review. Journal of Indian Academy of Oral Medicine and Radiology 2014;26(2):173-7.

[10] Venugopal A, UmaMaheswari TN. Expression of matrix metalloproteinase - 9 in oral potentially malignant disorders: a systematic review. J Oral Maxillofac Pathol 2016;20(3):474-9.

[11] Venugopal A, UmaMaheswari TN. Drug delivery tailored for the need- case series of oral lichen planus. J Young Pharm 2018;10(2):246-8.

[12] Prabakaran SP, Muthukrishnan A. Assessing field change through the expression of cytokeratin 18 and 19 in areas of erosive oral lichen planus and adjoining normal mucosa. Journal of Indian Academy of Oral Medicine and Radiology 2018;30(3):201-6.

[13] Gujjar P, Zingade J, Patil S, et al. Recent update on treatment modalities of oral lichen planus - a review. IJSS Case Reports \& Reviews 2015;2(4):40-4.

[14] Kiran CS, Ramaswamy P, Santosh N. Comparison of steroids and calcineurin inhibitors in the management of oral lichen planus- a meta - analysis. EC Dental Science 2018;17(5):606-12.

[15] Sivaraman S, Santham K, Nelson A, et al. A randomized triple - blind clinical trial to compare the effectiveness of topical triamcinolone acetonate (0.1\%), clobetasol propionate $(0.05 \%)$ and tacrolimus orabase $(0.03 \%)$ in the management of oral lichen planus. J Pharm Bioallied Sci 2016;8(Suppl 1):S86-9.

[16] Bennion SD, Middleton MH, David-Bajar KM, et al. In three types of interface dermatitis, different patterns of expression of intercellular adhesion molecule - 1 (ICAM 1) indicate different triggers of disease. J Invest Dermatol 1995;105(Suppl 1):71S-9S.

[17] Zalewska A, Brzezińska-Błaszczyk E, Omulecki A, et al. Functional studies of skin mast cells in lichen planus. Arch Dermatol Res 1997;289(5):261-4.

[18] Pestelli E, Caproni M, Giomi B, et al. Cetirizine reduces the number of tryptase - positive mast cells in psoriatic patients: a double - blind controlled study. Int J Tissue React 2001;23(3):97-103.

[19] Miyagawa F, Danno K, Uehara M. Erythema gyratum repens responding to cetirizine hydrochloride. J Dermatol 2002;29(11):731-4.

[20] Sehgal VN, Jain S, Kumar S, et al. Generalized lichen nitidus in a child's response to cetirizine dihydrochloride/levamisol. Australas J Dermatol 1998;39(1):60.

[21] D’Ovidio R, Rossi A, Di Prima TM. Therapeutic hotline: effectiveness of the association of cetirizine and topical steroids in lichen planus pilaris - an open - label clinical trial. Dermatologic Therapy 2010;23(5):547-52.

[22] Escudier M, Ahmed N, Shirlaw P, et al. A scoring system for mucosal disease severity with special reference to oral lichen planus. Br J Dermatol 2007;157(4):765-70.

[23] Mishra SS, Umamaheswari TN. Evaluation of oxidative stress in oral lichen planus using Malonaldehyde: a systematic review. J of Saudi Society of Dermatology \& Dermatologic Surgery 2014.

[24] Gupta S, Jawanda MK. Oral lichen planus: an update on etiology, pathogenesis, clinical presentation, diagnosis and management. Indian J Dermatol 2015;60(3):222-9.

[25] Namrata M, Kumar JV. Assessment of quality of life in patients with chronic oral mucosal diseases: a questionnaire - based study. International Journal of Orofacial Biology 2017;1(1):24-7.

[26] Subha M, Arvind M. Role of magnetic resonance imaging in evaluation of trigeminal neuralgia with its anatomical correlation. Biomedical and Pharmacology Journal 2019;12(1):289-96.

[27] Setterfield J, Shirlaw PJ, Kerr-Muir M, et al. Mucous membrane pemphigoid: a dual circulating antibody response with IgG and IgA signifies a more severe and persistent disease. Br J Dermatol 1998;138(4):602-10.

[28] Vadivel JK, Govindarajan M, Somasundaram E, et al. Mast cell expression in oral lichen planus: a systematic review. J Investig Clin Dent 2019;10(4):e12457.

[29] Rohini S, Sherlin HJ, Jayaraj G. Prevalence of oral mucosal lesions among elderly population in Chennai: a survey. J Oral Med Oral Surg 2020;26(1):10.

[30] Lauritano D, Arrica M, Lucchese A, et al. Oral lichen planus clinical characteristics in Italian patients: a retrospective analysis Head \& Face Medicine 2016;12:18.

[31] Budimir V, Richter I, Andabak-Rogulj A, et al. Oral lichen planus - retrospective study of 563 Croatian patients. Med Oral Patol Oral Cir Bucal 2014;19(3):e255-60.

[32] Kini R, Nagaratna DV, Saha A. Therapeutic management of oral lichen planus: a review for the clinicians. World Journal of Dentistry 2011;2(3):249-53.

[33] Sharma L, Mishra MK. A comparative study of Puvasol therapy in lichen planus. Indian J Dermatol Venereol Leprol 2003;69(3):212-3. 